\title{
Methods for prevention of acute post-endoscopic retrograde cholangiopancreatography pancreatitis
}

\author{
Kamil Jaszczuk ${ }^{1}$, Michał Lipiński ${ }^{1}$, Grażyna Rydzewska ${ }^{1,2}$ \\ ${ }^{1}$ Department of Internal Medicine and Gastroenterology with IBD Subdivision, Central Clinical Hospital of the Ministry \\ of the Interior, Warsaw, Poland \\ ${ }^{2}$ Faculty of Medicine and Health Sciences, Jan Kochanowski University, Kielce, Poland
}

Gastroenterology Rev 2020; 15 (2): 98-102

DOI: https://doi.org/10.5114/pg.2020.95555

Key words: post-endoscopic retrograde cholangiopancreatography pancreatitis, endoscopic retrograde cholangiopancreatography, nonsteroidal anti-inflammatory drugs, pancreatic duct stents.

Address for correspondence: Kamil Jaszczuk, Department of Internal Medicine and Gastroenterology with IBD Subdivision, Central Clinical Hospital of the Ministry of the Interior, 137 Woloska St, 02-507 Warsaw, Poland, e-mail: kamjas2@wp.eu

\begin{abstract}
Acute pancreatitis is the most common complication of endoscopic retrograde cholangiopancreatography (ERCP), with incidence rates ranging between $2 \%$ and $16 \%$. In addition to being experienced in endoscopic procedures and having knowledge of the patient qualification criteria, physicians should also be aware of the patient and procedure-related risk factors responsible for post-ERCP pancreatitis (PEP). Intrarectal administration of nonsteroidal anti-inflammatory drugs and pancreatic duct stenting were demonstrated to be efficient in high-risk patients. This review provides a broader summary of pharmacological methods and techniques aimed at reducing the risk of PEP.
\end{abstract}

\section{Introduction}

Acute pancreatitis (AP) is the most common complication of endoscopic retrograde cholangiopancreatography (ERCP), with incidence rates ranging between $2 \%$ and $16 \%$ [1]. Post-ECRP pancreatitis (PEP) may occasionally lead to death and is a cause of higher hospitalisation costs. Analyses show that severe disease may develop in $5 \%$ of PEP patients. When only high-risk patients are taken into account, this percentage rises to $25 \%$ [2].

The 1992 Atlanta classification defined the terminology and grading of acute pancreatitis. In 2012, a revision was made to the Atlanta classification with regard to definition of acute pancreatitis and its types (Table I) [3]. Acute pancreatitis is defined on the basis of symptoms and results of laboratory investigations and imaging scans. Diagnosis requires any two of the following three criteria being met: epigastric pain, a three-fold increase in amylase or lipase, and typical features of AP in imaging scans (abdominal ultrasound, CT, or MRI scans). Post-ECRP pancreatitis was defined as a consensus statement and described in 1991 by Cotton et al. Definition includes: the presence of typical abdominal pain, a three- fold increase in pancreatic enzyme activity levels as compared to the upper limit of normal within $24 \mathrm{~h}$ from the procedure, and a necessity to continue hospitalisation for at least two days. According to the consensus, the severity of PEP is defined on the basis of the duration of hospital stay: mild when hospitalisation lasts < 3 days, moderate when hospitalisation lasts 4-10 days, and severe when hospitalisation lasts $>10$ days [4].

It is very important that the physicians are aware of the patient- and procedure-related risk factors of PEP (Table II) [5].

Appropriate qualification of patients for the ERCP procedures plays an important role in the reduction of PEP-related hospitalisations [6]. Currently available techniques, including endoscopic ultrasound (EUS) or magnetic resonance, facilitate accurate evaluation of intra- and extrahepatic bile ducts, pancreas, or gallbladder. An increasing number of publications confirm the finding that EUS is more accurate and less expensive as a diagnostic method for proper qualification of patients for ERCP procedures $[7,8]$.

On the other hand, it is worthwhile presenting the conclusions from a study aimed at assessing the effect 
Table I. Acute pancreatitis severity grading according to Banks et al. [3]

\begin{tabular}{|c|c|c|}
\hline Mild AP & Moderate AP & Severe AP \\
\hline $\begin{array}{l}\text { Self-limiting disease without organ } \\
\text { insufficiency and/or local complications }\end{array}$ & $\begin{array}{c}\text { Presence of local complications, transient } \\
(<48 \mathrm{~h}) \text { organ insufficiency, and/or } \\
\text { concomitant exacerbation of background } \\
\text { diseases }\end{array}$ & $\begin{array}{l}\text { Single- or multiorgan insufficiency lasting } \\
\qquad 48 \mathrm{~h}\end{array}$ \\
\hline
\end{tabular}

Table II. PEP risk factors

\begin{tabular}{lr} 
Patient & \multicolumn{1}{c}{ Procedure } \\
\hline Age $<55$ years & Difficult cannulation, prolonged cannulation of pancreatic duct \\
\hline History of PEP & Biliary, pancreatic sphincterectomy (SE) \\
\hline Normal bilirubin levels & Ampulla of Vater balloon dilatation \\
\hline Female gender & Ampullectomy \\
\hline History of pancreatitis & Contrast within the pancreatic duct \\
\hline Sphincter of Oddi dysfunction & Self-expandable metallic stent placement \\
\hline Narrow bile ducts & Endoscopist's experience
\end{tabular}

of patient age on the risk and natural history of PEP. A total of 2688 patients undergoing their first ERCP procedure were qualified for the study and were divided into two groups: patients below 75 years of age (group 1) and patients above 75 years of age (group 2). The incidence of PEP was $5.2 \%$ in group 1 and $4 \%$ in group 2 $(p=N S)$; no significant differences were observed between the two groups of patients in terms of disease severity. PEP episodes were treated in a standard fashion and were free of other complications. It was therefore concluded that the ageing of society has no effect on the prevalence and intensity of PEP [9].

It is also worth mentioning that the incidence of ERCP-related adverse events in patients diagnosed with autoimmune pancreatitis type 1 (AIP 1) was low [10].

\section{Endoscopic methods}

Recent years have witnessed the appearance of publications and scientific evidence confirming the benefits of prophylactic stenting of the pancreatic tract during the ERCP procedure. Stent placement was found to reduce the pressure within the pancreatic duct following biliary sphincterectomy (SE) and to lower the incidence of PEP [11]. Another clinical trial examined the impact of stent size on the prevention of PEP. The $3 \mathrm{Fr}$ stents were shown to be associated with lower rates of PEP and pancreatic duct disruption, compared to $5 \mathrm{Fr}$ stents [12]. On the other hand, a study published in 2017 suggested no additional benefit of stenting as compared to the use of intra- rectal NSAID suppositories in the prevention of PEP in high-risk patients [13].

\section{Pharmacological methods \\ Nonsteroidal anti-inflammatory drugs (NSAIDs)}

Nonsteroidal anti-inflammatory drugs are strong inhibitors of phospholipase A2, a key modulator within the cascade responsible for clinical symptoms of PEP. A study carried out to assess the efficacy of intrarectal diclofenac, published in 2003, showed that the drug could reduce the incidence of PEP if administered immediately following the ERCP procedure [14]. Numerous other studies warranting the use of NSAIDs before or immediately after ERCP were published in the following years. In 2017, one study was published with a conclusion suggesting that diclofenac had no beneficial effect on the risk of PEP [15]. However, the same year witnessed the publication of two meta-analyses from China, in which the safety and efficacy of intrarectal diclofenac were demonstrated $[16,17]$.

In 2018, a large meta-analysis of data spanning from 1990 to 2017 was published. The authors concluded that both indomethacin and diclofenac, when administered via the intrarectal route, effectively prevented PEP in high- and moderate-risk patients [18].

\section{Nitrates}

The hypothetical mechanism of action of these drugs in the prevention of PEP consists of tone reduc- 
tion of the sphincter of Oddi. However, drugs from this group found no wider use in the prevention of postERCP pancreatitis [19]. Another study suggested that combination of indomethacin and sublingual nitrates administered prior to ERCP reduced the risk of PEP more efficiently than NSAIDs. However, no further results have been published on the topic over the subsequent 4 years.

\section{Aggressive intravenous fluid resuscitation}

An increasing body of evidence suggests that aggressive intravenous fluid resuscitation (IVFR) may reduce the incidence of pancreatitis. 2017 and 2018 witnessed publication of studies in which Ringer's lactate solution (RLS), when administered immediately after ERCP in a bolus of $20 \mathrm{ml} / \mathrm{kg}$ followed by infusion of $2 \mathrm{ml} / \mathrm{kg} / \mathrm{h}$ for $8 \mathrm{~h}$, was more efficient than intrarectal indomethacin and showed better preventive effects compared to a standard supply of crystalloids in the prevention of PEP in moderate- to high-risk patients [20-22].

\section{Somatostatin and octreotide}

Somatostatin, a strong inhibitor of pancreatic exocrine function, was found to prevent or alleviate pancreatitis and affect the function of the sphincter of Oddi. A study published in 2016 revealed that high-dose somatostatin administered over 12 hours could significantly reduce the frequency of post-ERCP pancreatitis (11.3\% vs. $4.9 \%)$. At the same time, low doses of somatostatin or bolus administration were ineffective in reducing the incidence of PEP $(8.5 \%$ as compared to $6.4 \%, O R=1.37,95 \% \mathrm{Cl}: 0.89-2.12, p=0.150,4.9 \%$ as compared to $9.3 \%, O R=0.39,95 \% \mathrm{Cl}: 0.14-1.04, p=$ 0.060) [23]. In 2018, a meta-analysis was conducted on all studies available within the PubMed, EMBASE, Cochrane, and Science citation index databases, to show that prophylactic long-term injections of somatostatin could significantly reduce the frequency of abdominal pain and hyperamylasaemia in high-risk patients after ERCP. The method is not recommended in patients at low risk of PEP [24].

Table III. Documented, clinically tested substances

\begin{tabular}{lc} 
Active & Non-active \\
\hline Indomethacin, NSAIDs [14-18] & ACC [29] \\
Pancreatic stents [11, 12] & Protease inhibitors [30] \\
Steroids [31] \\
Vitamin A, C, E [32] \\
Allopurinol [33] \\
Calcitonin [34] \\
Heparin [35]
\end{tabular}

\section{Antibiotic therapy}

As demonstrated by a retrospective study by Ishigaki et al., antibiotics do not reduce the risk of PEP or the incidence of post-ERCP pancreatitis [25].

\section{Cannabis indica}

A study published in 2018 demonstrated that the intake of cannabis derivatives was associated with a significant rise in PEP morbidity but not mortality rates [26].

\section{Prediction of PEP}

In June 2018, an interesting article was published regarding the usefulness of serum amylase and lipase determinations performed 2 and $4 \mathrm{~h}$ after ERCP. The measurements were shown that they can be useful in PEP forecasting [27]. Another study examined the serum levels of phosphates over the period of 12-24 h after ERCP; phosphate concentration was shown to be associated with the severity of PEP [28], but the topic requires further research on the potential use of serum phosphate levels as prognostic markers.

An interesting concept consists of the use of blood pressure cuffs to induce temporary ischaemia within the upper limb as a means to prevent PEP prior to the ERCP procedure - studies on the subject are underway at the Department of Internal Medicine and Gastroenterology with IBD Subdivision, Central Clinical Hospital of the Ministry of the Interior in Warsaw, Poland. Currently, the method is used mainly in cardiosurgery, e.g. as a means to reduce the incidence of acute renal damage. Despite the wide applicability of the induced ischaemia method, no studies assessing the efficacy of pancreatic protection following retrograde cholangiopancreatography are available in the literature. The study will aim at the assessment of the method's efficacy in reducing the incidence of acute pancreatitis following endoscopic retrograde cholangiopancreatography. Results are planned to be published in late 2019/ early 2020 .

\section{Conclusions}

Because PEP remains the most common complication of ERCP, measures are continuously being taken to reduce the incidence and severity of PEP episodes. These parameters may be reduced, e.g. by appropriate qualification of patients for ERCP procedures using appropriate diagnostic examinations and supported by appropriate endoscopist's experience. Table III lists the clinically tested substances, chemicals, and stents that may or may not be efficient in PEP prevention [29-35]. Ultimately, the guidelines of the American Society of 
Gastrointestinal Endoscopy (ASGE) and the European Society of Gastrointestinal Endoscopy (ESGE) recommend that intrarectal NSAIDs are used for prevention of PEP due to their low cost, simple administration, and good safety profile. In addition, the ASGE and ESGE suggest that pancreatic duct stenting and intravenous hydration using Ringer lactate solution may be considered as means of PEP prevention [36-39].

Due to the concerns associated with the ambiguous results of studies on the use of NSAIDs [15] in the prevention of PEP, further search for an optimum method to reduce the risk of these dangerous complications is warranted.

\section{Conflict of interest}

The authors declare no conflict of interest.

\section{References}

1. Kochar B, Akshintala VS, Afghani E, et al. Incidence, severity, and mortality of post-ERCP pancreatitis: a systematic review by using randomized, controlled trials. Gastrointest Endosc 2015; 81: 143-9.

2. Elmunzer BJ. Reducing the risk of post-endoscopic retrograde cholangiopancreatography pancreatitis. Dig Endosc 2017; 29: 749-57.

3. Banks PA, Bollen TL, Dervenis C, et al. Classification of acute pancreatitise2012: revision of the Atlanta classification and definitions by international consensus. Gut 2013; 62: 102-11.

4. Cotton PB, Lehman G, Vennes J, et al. Endoscopic sphincterotomy complications and their management: an attempt at consensus. Gastrointest Endosc 1991; 37: 383-93.

5. Chen JJ , Wang XM , Liu XQ, et al. Czynniki ryzyka zapalenia trzustki po ERCP: systematyczny przegląd badań klinicznych z dużą liczebnością próby w ciągu ostatnich 10 lat. Eur J Med Res 2014; 19: 26.

6. Chan E, Neeman T, Thomson A. Follow-up to determine unplanned hospitalization and complications after endoscopic retrograde cholangiopancreatography. ANZ J Surg 2018; 88: E142-6.

7. Moura DTH, de Moura EGH, Matuguma SE, et al. EUS-FNA versus ERCP for tissue diagnosis of suspect malignant biliary strictures: a prospective comparative study. Endosc Int Open 2018; 6: E769-77.

8. Bukhari M, Kowalski T, Nieto J, et al. An international, multicenter, comparative trial of EUS-guided gastrogastrostomy-assisted ERCP versus enteroscopy-assisted ERCP in patients with Roux-en-Y gastric bypass anatomy. Gastrointest Endosc 2018. 88: 486-94.

9. Katsinelos P, Lazaraki G, Chatzimavroudis G, et al. The impact of age on the incidence and severity of post-endoscopic retrograde cholangiopancreatography pancreatitis. Ann Gastroenterol 2018; 31: 96-101.

10. Naitoh I, Nakazawa T, Okumura F, et al. Endoscopic retrograde cholangiopancreatography-related adverse events in patients with type 1 autoimmune pancreatitis. Pancreatology 2016; 16: 78-82.
11. Li GD, Jia XY, Dong HY, et al. Pancreatic stent or rectal indomethacin-which better prevents post-ERCP pancreatitis? A propensity score matching analysis. Medicine 2016; 95: e2994.

12. Fujisawa T, Kagawa K, Ochiai K, et al. Prophylactic efficacy of 3- or 5-cm pancreatic stents for preventing post-ERCP pancreatitis: a prospective, randomized trial. J Clin Gastroenterol 2016; 50: e30-4.

13. Bekkali NL, Thomas T, Keane MG, et al. Preventing post-ERCP pancreatitis: the role of prophylactic pancreatic duct stenting in the rectal NSAID era. JOP 2017; 18: 316-9.

14. Murray B, Carter R, Imrie C, et al. Diclofenac reduces the incidence of acute pancreatitis after endoscopic retrograde cholangiopancreatography. Gastroenterology 2003; 124: 1786-91.

15. Rainio M, Lindström O, Udd M, et al. Diclofenac does not reduce the risk of post-endoscopic retrograde cholangiopancreatography pancreatitis in low-risk units. J Gastrointest Surg 2017; 21: 1270-7.

16. Hou YC, Hu Q, Huang J, et al. Efficacy and safety of rectal nonsteroidal anti-inflammatory drugs for prophylaxis against post-ERCP pancreatitis: a systematic review and meta-analysis. Sci Rep 2017; 7: 46650.

17. Li L, Han Z, Yuan H, et al. Nonsteroidal anti-inflammatory drugs reduce the incidence of post-endoscopic retrograde cholangiopancreatography pancreatitis: a meta-analysis. J Hepatobiliary Pancreat Sci 2017; 24: 520-9.

18. Lyu Y, Cheng Y, Wang B, et al. What is impact of nonsteroidal anti-inflammatory drugs in the prevention of post-endoscopic retrograde cholangiopancreatography pancreatitis: a metaanalysis of randomized controlled trials. BMC Gastroenterol 2018; 18: 106.

19. Bhatia V, Ahuja V, Acharya SK, et al A randomized controlled trial of valdecoxib and glyceryl trinitrate for the prevention of post-ERCP pancreatitis. J Clin Gastroenterol 2011; 45: 170-6.

20. Sotoudehmanesh R, Eloubeidi MA, Asgari AA, et al. A randomized trial of rectal indomethacin and sublingual nitrates to prevent post-ERCP pancreatitis. Am J Gastroenterol 2014; 109: 903-9.

21. Masjedizadeh A, Fathizadeh P, Aghamohamadi N. Comparative effectiveness of aggressive intravenous fluid resuscitation with lactated Ringer's solution and rectal indomethacin therapy in the prevention of pancreatitis after endoscopic retrograde cholangiopancreatography: a double blind randomised controlled clinical trial. Gastroenterology Rev 2017; 12: 271-6.

22. Park CH, Paik WH, Park ET, et al. Aggressive intravenous hydration with lactated Ringer's solution for prevention of postERCP pancreatitis: a prospective randomized multicenter clinical trial. Endoscopy 2018; 50: 378-85.

23. Pan SB, Geng XP. Meta-analysis: somatostatin for prophylaxis against post endoscopic retrograde cholangiopancreatography pancreatitis. Chin J Surg 2016; 54: 466-72.

24. Wang G, Xiao G, Xu L, et al Effect of somatostatin on prevention of post-endoscopic retrograde cholangiopancreatography pancreatitis and hyperamylasemia: a systematic review and meta-analysis. Pancreatology 2018; 18: 370-8.

25. Ishigaki T, Sasaki T, Serikawa M, et al. Evaluation of antibiotic use to prevent post-endoscopic retrograde cholangiopancreatography pancreatitis and cholangitis. Hepatogastroenterology 2015; 62: 417-24. 
26. Njei B, Sharma P, McCarty TR, et al. Cannabis use is associated with increased risk of post-endoscopic retrograde cholangiopancreatography pancreatitis: analysis of the US Nationwide Inpatient Sample Database, 2004-2014. Pancreas 2018; 47: 1142-9.

27. Minakari M, Sebghatollahi V, Sattari M, et al. Serum amylase and lipase levels for prediction of postendoscopic retrograde cholangiopancreatography pancreatitis. J Res Med Sci 2018; 23: 54.

28. Choi YH, Jang DK, Lee $\mathrm{SH}$, et al. Utility of serum phosphate as a marker for predicting the severity of post-endoscopic retrograde cholangiopancreatography pancreatitis. United European Gastroenterol J 2018; 6: 895-901.

29. Milewski J, Rydzewska G, Degowska M, et al. N-acetylcysteine does not prevent post-endoscopic retrograde cholangiopancreatography hyperamylasemia and acute pancreatitis. World J Gastroenterol 2006; 12: 3751-5.

30. Seta T, Noguchi Y, Shikata S, Nakayama T. Treatment of acute pancreatitis with protease inhibitors administered through intravenous infusion: an updated systematic review and meta-analysis. BMC Gastroenterol 2014; 14: 102.

31. Gloor B, Uhl W, Tcholakov O, et al. Hydrocortisone treatment of early SIRS in acute experimental pancreatitis. Dig Dis Sc 2001; 46: 2154-61.

32. Bansal D, Bhalla A, Bhasin DK, et al. Safety and efficacy of vitamin-based antioxidant therapy in patients with severe acute pancreatitis: a randomized controlled trial. Saudi J Gastroenterol 2011; 17: 174-9.

33. Bai Y, Gao J, Zhang W, et al. Meta-analysis: allopurinol in the prevention of postendoscopic retrograde cholangiopancreatography pancreatitis. Aliment Pharmacol Ther 2008; 28: 557-64.

34. Odes HS, Novis BN, Barbezat GO, et al. Effect of calcitonin on the serum amylase levels after endoscopic retrograde cholangiopancreatography. Digestion 1977; 16: 180-4.

35. Li S, Cao G, Chen X, et al. Low-dose heparin in the prevention of post endoscopic retrograde cholangiopancreatography pancreatitis: a systematic review and meta-analysis. Eur J Gastroenterol Hepatol 2012; 24: 477-81.

36. Dumonceau JM, Andriulli A, Elmunzer BJ, et al. Prophylaxis of post-ERCP pancreatitis: European Society of Gastrointestinal Endoscopy (ESGE) Guideline - Updated June 2014. Endoscopy 2014; 46: 799-815.

37. Chandrasekhara V, Khashab MA, Muthusamy VR, et al. Adverse events associated with ERCP. Gastrointest Endosc 2017; 85: 32-47.

38. Rydzewska G, Morisset J, Stimac D. New insights into pathogenesis, diagnosis, and treatment of pancreatic disorders. Gastroenterol Res Pract 2013; 2013: 305179.

39. Marek T, Nowakowska-Duława E, Baniukiewicz A, et al. Quality indicators for endoscopic retrograde cholangiopancreatography - guidelines from the Polish Society of Gastroenterology and the Association of Polish Surgeons. Gastroenterol Prakt 2015; 8: 39-62.

Received: 16.04.2019

Accepted: 23.04 .2019 